\title{
Design of Road Based on the Applicable Design Methods used in Western European Countries
}

\author{
Jūratė Vitkienè, Virgaudas Puodžiukas \\ Department of Roads, Vilnius Gediminas Technical University, Sauletekio al. 11, 10223 Vilnius, Lithuania
}

\begin{abstract}
The rapidly increasing motorization rate in Lithuania causes increasing problems in ensuring safe and convenient traffic on roads and streets. The current situation in Lithuania shows that the number of traffic accidents is still one of the highest in Europe, though every effort has been made to deal with this problem - the laws on traffic safety are created, huge funds are allocated for implementing a variety of safety measures, educational activities are carried out. This suggests that these only measures are not enough and it is necessary to look for new, radical, science-based solutions to ensure road safety. One of the solutions - having studied possibilities for the improvement of safety on roads to apply new methods of road design, taking into consideration the proven experience of the European Union, i.e., the newest road design rules. Design solutions for the reconstructed or newly constructed roads in Lithuania due to imperfect design methods may be unsuitable from the point of view of road safety, as well as Level of Service (LOS). This paper describes the up-to-date road design techniques used in Western European countries (especially in Germany) comparing them to the existing methods in Lithuania. Analysis is made, what are the biggest differences between design methods and what should be done in road design to improve safety and quality of roads in Lithuania.
\end{abstract}

Keywords: road safety; road design; road design rules; road harmonious; design methods.

\begin{tabular}{|ll}
\hline Nomenclature \\
LOS & Level of Service (level of traffic quality) \\
RAL & Richtlinien für die Anlage von Landstraßen \\
EKL & Entwurfsklasse von Landstraßen (design class in Germany) \\
$R$ & radius of the circle of curvature (m) \\
A & clothoid parameter \\
$\mathrm{H}_{\mathrm{K}}$ & radius of crest vertical curve \\
$\mathrm{H}_{\mathrm{w}}$ & radius of sag vertical curve \\
\hline
\end{tabular}

\section{Introduction}

Engineers build roads for the use of ordinary people. The design must of course be influenced by human traits and limitations of perception and the way drivers regulate their activity. Roads are first of all intended for the drivers to enable them to safely, conveniently, speedily and comfortably reach their destination, to carry freight or passengers. Road designers expect that the newly designed roads will look beautiful, will be easily and immediately perceived and recognized, functional, will have good connections with other roads and objects, and will be safe - with the lowest possible accident risk. However, on certain roads, even the newly built or reconstructed, unfortunately, accidents occur. Sometimes the reasons are obvious - design mistakes or violation of traffic rules, but sometimes - it is impossible to discover accident causes since the design and construction are carried out according to the rules and design standards. The limitations and the physiological, sensorimotor and cognitive principles of spatial perception can reliably explain accidents. They provide a solid basis for developing effective remedies. In Germany over the past 10 years about 1500 technically "unexplainable" accidents on older as well as newly built rural roads have been investigated [1]. About $70 \%$ of these accidents were caused by misperception, overloading of drivers' ability to perceive and react, deficiencies in optical orientation and guidance, and

Corresponding author: Jūratė Vitkienė. E-mail address: jurate.vitkiene@vgtu.lt

http://dx.doi.org/10.3846/enviro.2014.175

(C) 2014 The Authors. Published by VGTU Press. This is an open-access article distributed under the terms of the Creative Commons Attribution License, which permits unrestricted use, distribution, and reproduction in any medium, provided the original author and source are credited. 
inconsistencies between drivers' expectations or habits on the one hand and design/signage on the other. All these causes could be clearly related to the laws of human spatial perception and orientation.

Road safety is ensured by suitable road design and construction, effective traffic organization, road pavement of good quality, intersections, pedestrian paths and other safety elements: various types of islands (in conventional intersections and roundabouts); median (with safety barriers or vegetation); roadside safety barriers; marker posts and other posts; speed humps; kerbs; fences; road signs, etc. One of the essential road safety tasks - to maintain all vehicles within the limits of traffic lane, to prevent them from going off the road, running into obstacle or overturning. In a design stage, both when building new and reconstructing the existing roads the specialists seek and analysis solutions that could improve road safety and prevent road accidents. Therefore, having studied possibilities for the improvement of safety on roads, it is necessary to start applying new methods of road design, taking into consideration the proven experience of the European Union, i.e., the newest road design rules. In general, some of the most comprehensive and inclusive examples were found in German [2], [3], Dutch [4-6] and other [7], [8] standards. This paper compares the current national road design standards for rural distributor roads.

\section{The main problems}

Over the past several decades design standards, usually based on laws of physics or empirical data, have been used by designers. Increasingly, designers have come under pressure to reduce construction costs by using lower standards on the assumption that even minimum standards are always acceptable. Design dimensions that do not meet the standards do not necessarily result in unacceptable design, and dimensions that meet the standards do not guarantee the acceptable and safe design. In assessing the quality of design, it is not appropriate to simply consider a checklist of standards. The design has to be reviewed with judgment; the standards merely assist the reviewer in making judgments. Every detail having a relation to any human factors element should be included into the standards and properly explained. Most of the accidents on highways which were correctly designed following the standards, with proper involvement of human factors criteria (especially for spatial perception) best practices found in different countries; most of these incidents will be solved. One of those new methods of road design (not included in the Lithuanian design rules) is the analysis of a perspective view of the road, i.e., how the driver sees the road in perspective and in space and how he perceives it.

Road geometry is usually studied and designed in terms of three components - horizontal alignment, vertical alignment and cross-section - which define a roadway as three-dimensional ribbon. The design of those three components is made sequentially (in a static or in a dynamic way) and they should be coordinated according to the existing design standards. It is mainly the horizontal and vertical alignments that should be well coordinated in order to have a good result in the threedimensional alignment. Such coordination is better achieved using software tools that show the road project in three dimensions, covering the right-of-way and adjacent terrain - how the road fits into the landscape.

When road geometry was studied using curve templates (circles, clothoids and cubic parabolas) on paper maps and terrain profiles and only some of the cross-sections were drawn at the most difficult points to see how the road is adapted to the terrain, it took much more time than it does now. Designers took advantage of this longer time for in-depth analysis of multiple solutions which were mapped using different colours. Nowadays, this longer time does not exist, and sometimes the road project has political or economic deadlines that are incompatible with a well-thought-out and well-reviewed road design.

It is quite difficult, if not impossible, to comply with all the constraints imposed on road geometric design, and to achieve a solution that optimizes most of them. Topography, geology, geotechnics, land use, drainage, environment, preservation of historical and cultural values, traffic operations, road equipment, tunnels, bridges, viaducts and other engineering structures, median openings, emergency escape ramps, roadside design, intersections, rest area and tollbooth locations, landscape treatment and cost-benefit analysis are some of the multiple constraints that the designer must keep in mind during the geometric design process.

Within this process, the designer creates a three-dimensional field of view for the driver. He should therefore have all the information about complementary designs (road equipment, engineering structures, landscape treatment, etc.) throughout the road design process, from the feasibility and preliminary design stages to the detailed design stage. He should also have basic knowledge and experience in how the three-dimensional field of view can be configured to ensure safe and reliable spatial perception and optical guidance.

It is essential in road design that the design standards should be respected in all design phases by all members of the design team, mainly by the geometric designer who has a very difficult task of modelling the three-dimensional sculpture consisting of the road and its environment. Therefore, he should also have a thorough knowledge and understanding of spatial perception. For this reason, it is necessary to change the standards by integrating new methods of road design and especially the effect of spatial perception and optical guidance on users. 


\section{The best practice and the largest differences in design methods}

\subsection{Horizontal Straights}

Drivers adapt their speed to the given road situation. A very small number of contrasting objects leads to monotony and to both reduced performance and reactivity. To avoid monotony, the driver subconsciously changes his driving behavior in order to increase information input: he sharply turns, brakes or - in most cases - increases speed.

The road environment should be well structured through:

- fixation objects that attract drivers' attention, but do not distract;

- a sinuous "rhythmic" alignment (sufficient curvature).

The German RAL [2] advises limiting the maximum length of straight sections to $1500 \mathrm{~m}$. If there is a need for adaptation to the environment or other constraints, longer straight sections are possible.

\subsection{Horizontal circular curves}

The road must create a smooth, slowly winding spatial line allowing the driver to travel on the whole road section at only slightly changing speed. In road design rules of USA and some Western European countries, for example, Germany, in order to make the route smooth the requirements are set to not only the radii of horizontal circular curves (compared to Lithuanian design rules) but also to the minimum lengths for curves (Table 1).

Table 1. Minimum radii and minimum lengths for circular curves [2]

\begin{tabular}{llll}
\hline Design class & Speed limit $(\mathrm{km} / \mathrm{h})$ & Minimum radii $(\mathrm{m})$ & $\begin{array}{l}\text { Minimum lengths for } \\
\text { circular curves }(\mathrm{m})\end{array}$ \\
\hline EKL 1 & 110 & $\geq 500$ & 70 \\
EKL 2 & 100 & $350-900$ & 60 \\
EKL 3 & 90 & $250-600$ & 50 \\
EKL 4 & 70 & $150-300$ & 40 \\
\hline
\end{tabular}

The defined minimum lengths for horizontal circular curves do not allow designers to use very short curves and this enable to reduce road bendiness dangerous to traffic. Besides, this regulated length enables to determine a design step in horizontal alignment which depends on design speed. In this way, limitations are set to road bendiness which influences LOS and it is ensured that the road alignment is safe, smooth and convenient for the drivers.

To ensure safe transitions, the radii of curves after straight sections should have a balanced relation to the length of the straight section. Both directions of traffic should then be considered.

Straight sections between curves of the same direction should be avoided. If this is not possible, the minimum length of the straight section should be 1.5 times the radius of the smaller curve.

\subsection{Transition curves}

Transition curves are necessary on all roads. The only exceptions to this rule are cases where a slight change in the angle of the curve ( $\gamma$ is less than $9^{\circ}$, flat curve) makes it impossible to have a transition curve followed by a circular curve followed by a transition curve. Also, if the horizontal circular curves of radius is more than 1000 meters. In such cases, the length of circular curve, depending on the design class, shall be not less than indicated in Table 2.

Table 2. Minimum lengths for circular curves where no transition curves are used [2]

\begin{tabular}{ll}
\hline Design class & Minimum lengths for circular curves $(m)$ \\
\hline EKL 1 & 200 \\
EKL 2 & 200 \\
EKL 3 & 150 \\
EKL 4 & 100 \\
\hline
\end{tabular}

The Lithuanian road design rules [9] allow designing roads without transition curves, i.e., they are only recommended. However, transition curves are necessary on all roads since the purpose of transition curve is:

- to allow for superelevation development between the different crossfalls;

- to allow for gradual steering in and out of the curve and in so doing;

- to ensure a continual change in the centrifugal acceleration that occurs when driving in a curve;

- to create a swift and optically satisfactory alignment by gradually changing the curvature. 
The German RAL [2] (Fig. 1) shows the various element sequences in which transition curves are used.

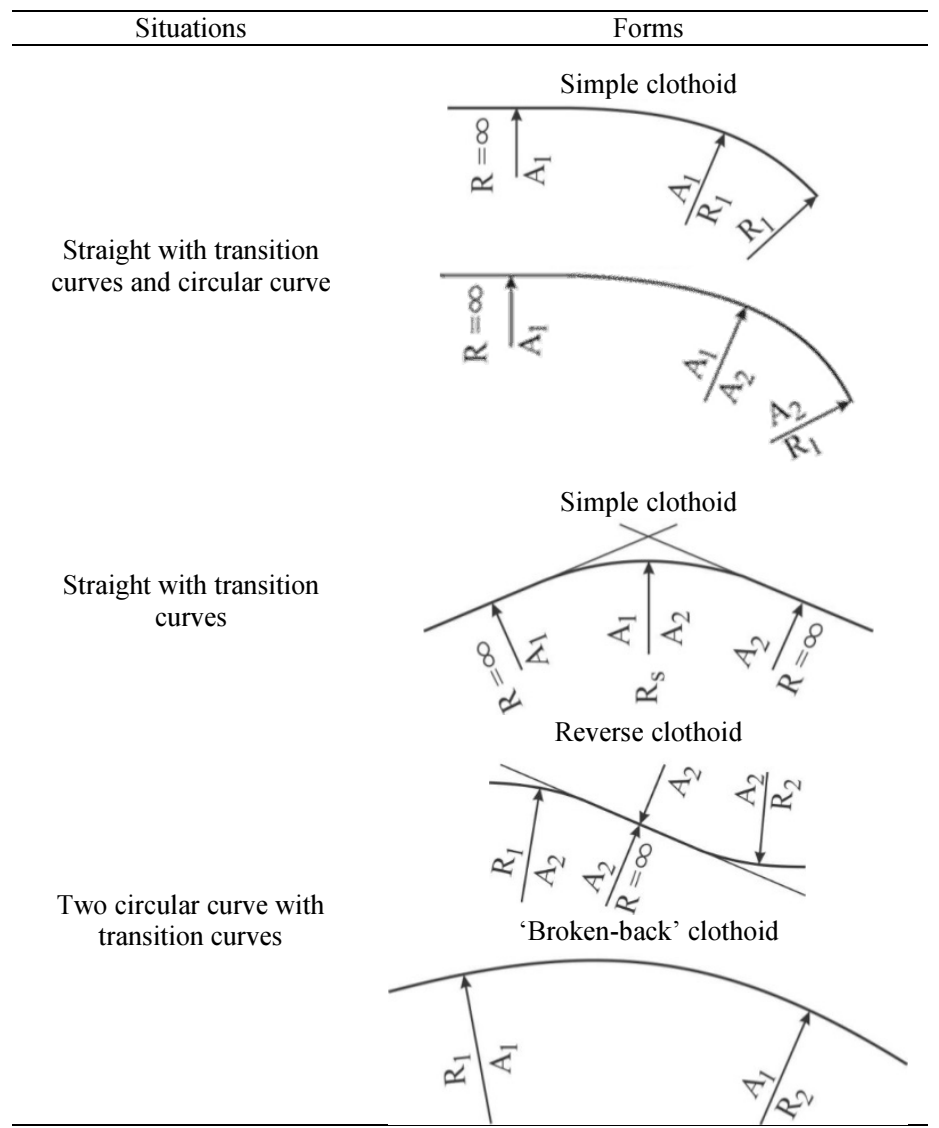

Fig. 1. Situations in which transition curves are used [2]

\subsection{Crest and sag vertical curves}

In almost all USA and European Union countries the road design rules require to necessarily use vertical (both crest and sag) curves in the ruptures of design line of vertical alignment. However, in Lithuanian road design rules the vertical curves in certain cases can be avoided.

Road ruptures that occur when changing a gradient of design line create many inconveniences for the travelling vehicles. In crest ruptures visibility reduces, besides, if there is a small-radius vertical curve the vehicle can lose control (stability) since the front axle load considerably decreases. In sag ruptures of design line with a sudden change in driving direction the vehicle springs become overloaded, the passengers feel unpleasant bump, etc. To avoid all this, in the ruptures of design line it should be recommended to use vertical curves of sufficiently large radius.

To make the route smooth the German road design rules give the requirements to not only the radii of crest and sag vertical curves (compared to Lithuanian road design rules) but also to the minimum lengths of tangents (Table 3 ).

Table 3. Minimum radii for crests and sags and minimum tangent lengths [2]

\begin{tabular}{llcl}
\hline Design class & $\begin{array}{l}\text { Minimum radii for } \\
\text { crests }(\mathrm{m})\end{array}$ & $\begin{array}{l}\text { Minimum radii for } \\
\text { sags }(m)\end{array}$ & $\begin{array}{l}\text { Minimum tangent } \\
\text { lengths }(m)\end{array}$ \\
\hline EKL 1 & $\geq 8000$ & $\geq 4000$ & 100 \\
EKL 2 & $\geq 5000$ & $\geq 3000$ & 85 \\
EKL 3 & $\geq 3000$ & $\geq 1800$ & 70 \\
EKL 4 & $\geq 2400$ & $\geq 1600$ & 55 \\
\hline
\end{tabular}

The defined minimum length of tangent does not allow designers to use very short vertical curves and this enables to reduce the number of ruptures in vertical alignment. Besides, this regulated length of tangents makes it possible to calculate the lowest distance between the ruptures of design line, i.e., to determine a design step in vertical alignment which depends on design speed. In this way, limitations are set to road waviness which influences LOS and it is ensured that the road alignment is safe, smooth and convenient for the drivers. 
Based on the experience of foreign countries the radii of crest and sag vertical curves shall be selected in a way that:

- together with the horizontal alignment elements they create a balanced three-dimensional alignment;

- they ensure road safety by ensuring that stopping sight distances are met;

- they are as well as possible adapted to fit the surrounding topography and they preserve the landscape.

\subsection{Elements of three-dimensional alignment}

A spatial view of a combination of road elements makes the essential influence on driving behaviour and road safety. Therefore, it is necessary to take into consideration the principles of spatial design of smooth alignment.

The road alignment shall be designed as optically smooth spatial line by combining the elements of horizontal and vertical alignment in-between and also with the surrounding landscape taking into consideration their impact on traffic conditions and visual perception of road, i.e., the road alignment must be completely clear, timely recognizable, perceivable and unambiguous for the drivers. This is regulated in the Lithuanian road design rules, however, they do not tell or explain how to achieve this, how to design road which would meet all the design principles of optically smooth alignment.

A spatial smoothness of alignment is created when the chosen parameters and combinations of alignment elements ensure that a perspective view of road alignment is incorrupt.

The roadway as seen by the driver comprises the pavement, slopes of cuttings and embankments, and the surrounding environment that does not actually belong to the road (but to the natural environment or populated area). The geometry of the roadway is specified by three separate aspects of design: the horizontal alignment, the vertical alignment, and the cross section.

In view of the fact that the road design comprises three different (3D) aspects, it is not always easy to appreciate the three-dimensional result. Therefore, German RAL [2] recommends in order to get an idea of the 3D impact of the road, specific 3D elements are defined. Each of these elements comprises one horizontal and one vertical alignment element. For these standardized 3D elements perspective views of the roadway are provided in Fig. 3 (horizontal straight) and Fig. 4 (horizontal curve).

On a basis these elements the above perspective views allow for a first approximate assessment of the impact of the three-dimensional (or spatial) alignment. A comprehensive inspection of the three-dimensional alignment is only possible when using perspective views that are generated for each section of road to be assessed. In this regard, the drivers' perspective is the only useful perspective view when it comes to evaluating the course of the road. Perspective views can be developed using appropriate planning programme modules and the digital models of the terrain and the road including the slopes in surrounding areas.

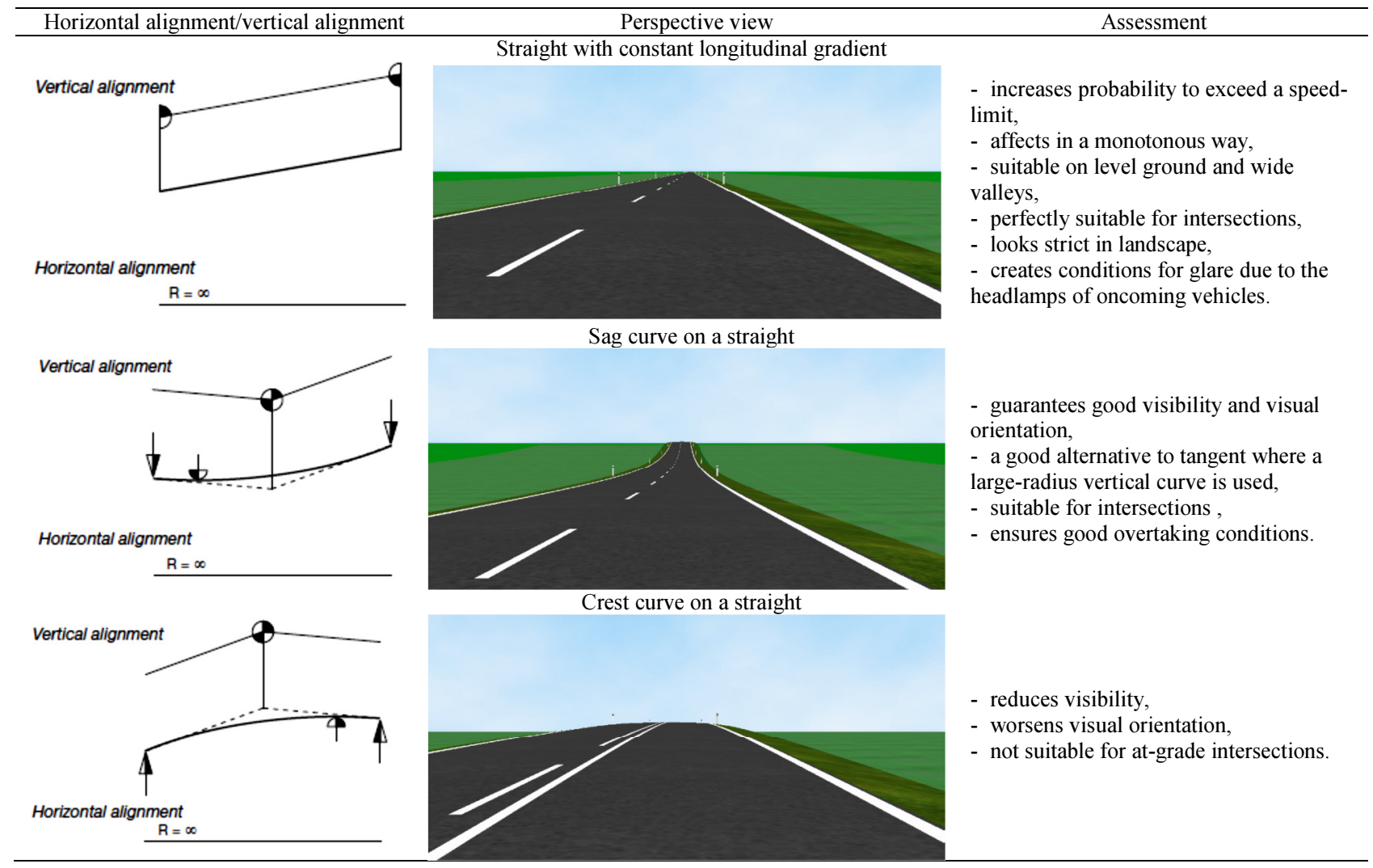

Fig. 2. Spatial elements of horizontal straights (superimposition of horizontal and vertical alignment design elements and including cross-sections) [2] 


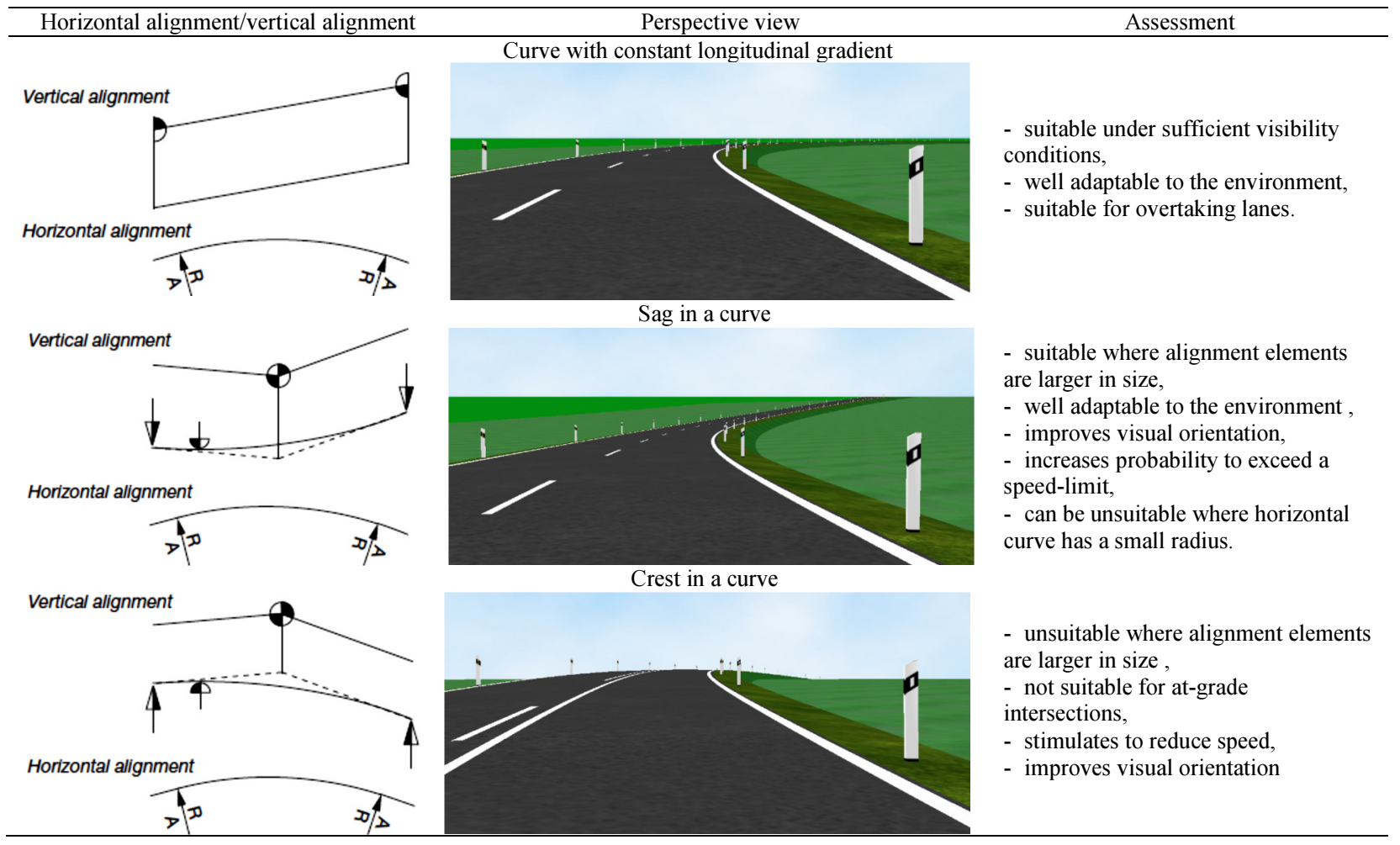

Fig. 3. Spatial elements of horizontal curves (superimposition of horizontal and vertical alignment design elements and including cross-sections) [2]

\subsection{Design of roads}

Due to wrongly designed spatial elements or their combinations the road may have many deficiencies which will affect driving behaviour and road safety. Table 4 gives the main deficiencies of roads and their impact on road safety that are recommended to be taken into consideration by the road design standards of the European Union countries (especially Germany).

Table 4. Road shortcomings and their impact on road safety [2]

\begin{tabular}{ll}
\hline Deficiency & Impact on road safety \\
\hline Invisible zones (ascent/descent) & high \\
Invisible start of a bend (unclear direction) & high \\
Outstretched bend in depression & average \\
Curvy bend on peak & low \\
\hline
\end{tabular}

To ensure visibility on a long road section one should avoid such combinations of spatial elements which cause invisible zones (ascent/descent) on the road and unclear alignment direction.

On invisible sections it is impossible to create safe overtaking conditions. Therefore, a combination of spatial elements where short sag vertical curves are designed, causing invisible zones, is unallowable (Fig. 4). In this case, a radius of vertical curve shall be increased and if this is impossible, engineering measures shall be applied to restrict overtaking.

Invisible start of a bend refers to the situation when a driver from at least $75 \mathrm{~m}$ distance is not able to see in front the start of a bend at least to the point where the change in alignment direction is $3.1^{\circ}$. In order to guarantee recognisability of the start of a bend, the start of horizontal curve shall begin earlier than the start of vertical curve.

In depression, i.e., in sag vertical curve, horizontal curve seems more outstretched (Fig. 5), and in crest vertical curve more curvy (Fig. 5) than on bend with continual longitudinal gradient. The size (visibility) of these road deficiencies are influenced by a ratio of horizontal and vertical curve radius $\left(\mathrm{R} / \mathrm{H}_{\mathrm{W}}\right.$ ir $\left.\mathrm{R} / \mathrm{H}_{\mathrm{K}}\right)$. 


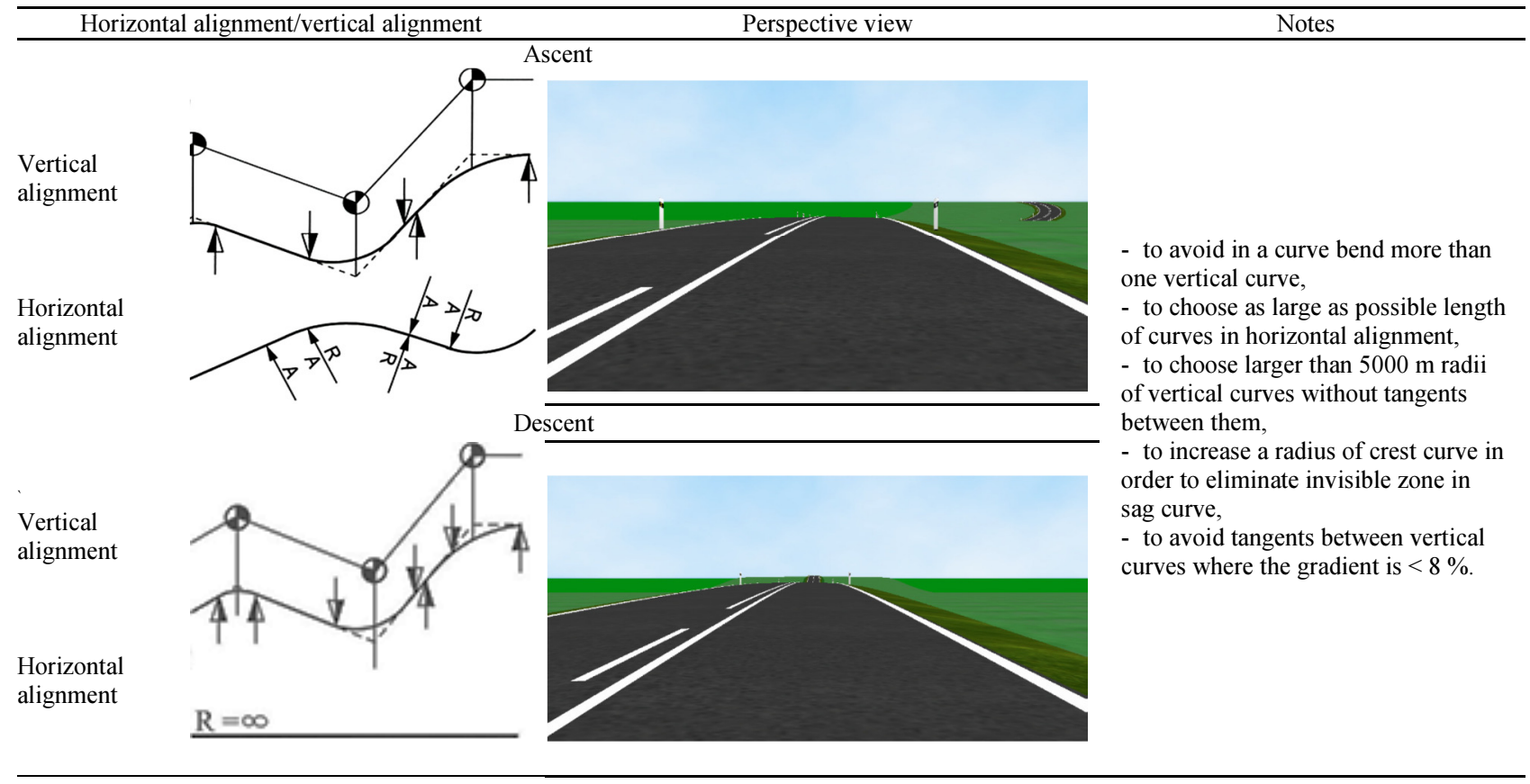

Fig. 4. Deficiencies of road causing invisible zones [2]

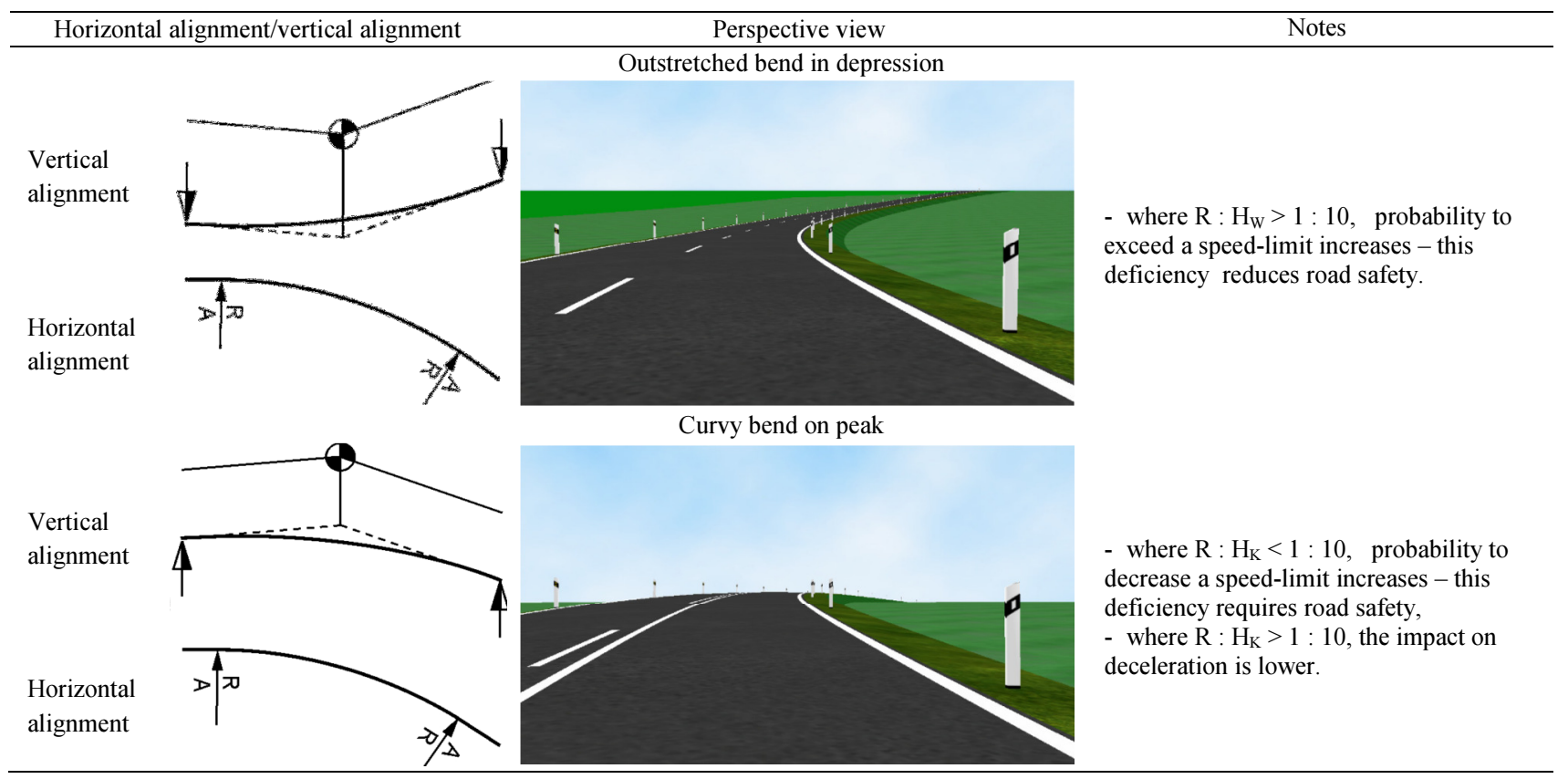

Fig. 5. Deficiencies where road bend seems too overstretched or curvy [2]

Non-smoothness (ruptures, optical distortions) is caused by the variable parameters of alignment elements where in long straight sections or on bends very short sag vertical curves are designed, also where between long straight sections and especially with continual longitudinal gradient short horizontal curves are designed (Fig. 6).

Having made a perspective view of road alignment and having analyzed its deficiencies the corrections of both horizontal and vertical alignments are carried out which will improve road smoothness. 


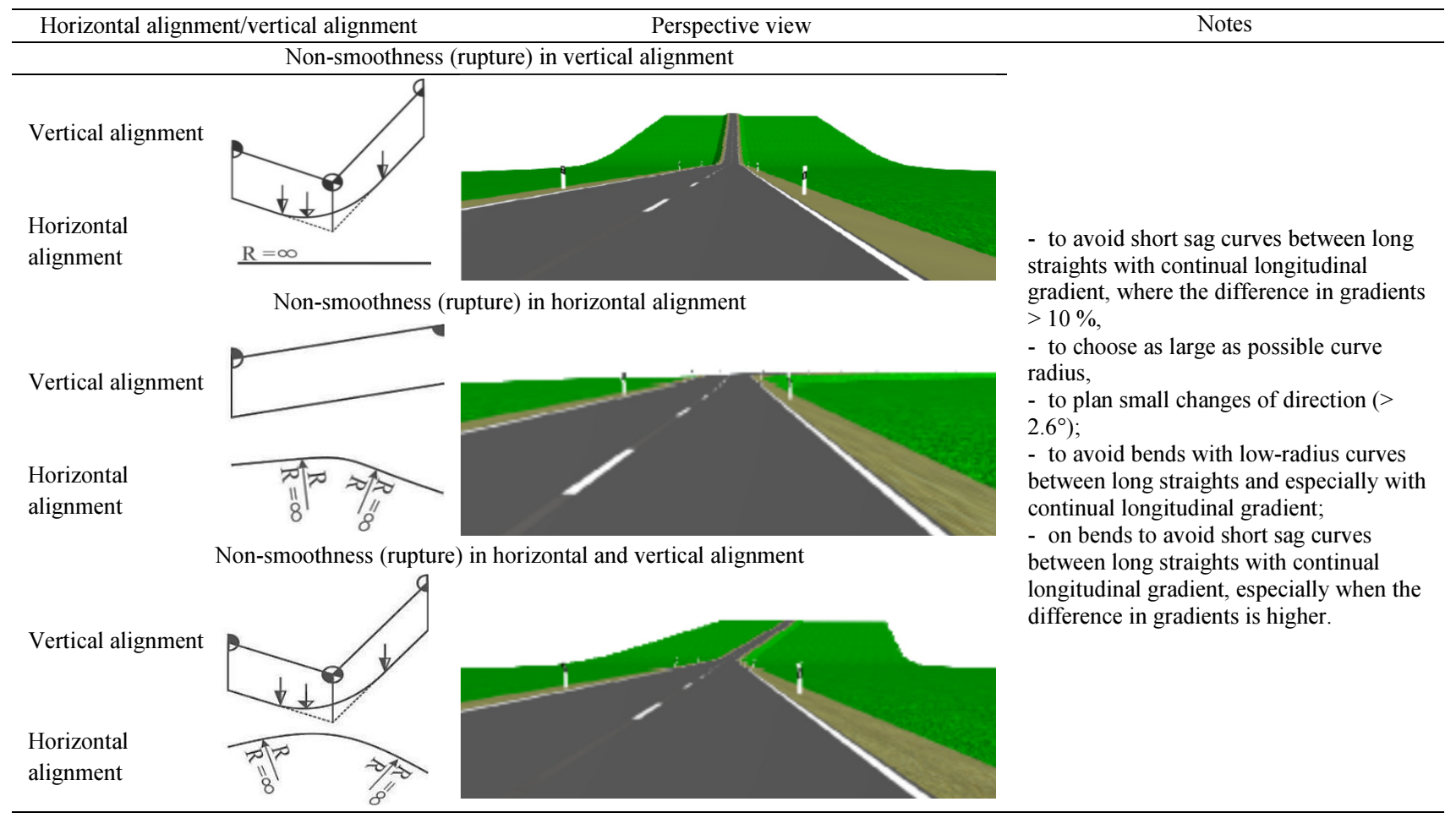

Fig. 6. Deficiency where road looks unsmooth (with ruptures) [2]

\section{Conclusions}

Taking into consideration the proven experience of European Union, the design solutions for reconstructed or newly constructed roads in Lithuania due to imperfect design methods may be unsuitable from the point of view of road safety, as well as LOS.

Based on the design methods used in Western European countries and having studied possibilities for the improvement of road safety, it is suggested to apply in Lithuania new methods of road design and to take into consideration the following recommendations:

- The design rules should be paid a larger attention to designing a smooth, safe and convenient road alignment and should set requirements on how to achieve this safety, smoothness and convenience;

- When designing roads it is necessary to apply the principles of spatial design of smooth alignment, since a spatial view of road elements combination has the essential effect on driving behaviour and road safety;

- The road shall be designed taking into consideration the impact of road elements on traffic conditions and visual perception of road, i.e., the road must be completely clear, timely recognizable, perceivable and unambiguous for the drivers;

- It is advisable to limit the maximum length of straight sections to $1500 \mathrm{~m}$. If needed to be adapted to the environment or other constraints, longer straight sections are possible;

- To ensure smooth road alignment, when designing vertical alignment it would be necessary to avoid frequent ruptures of design line and to reject ruptures where vertical curve is not used;

- To make road alignment smooth it is recommended to define in the design rules the least design step between the ruptures of design line depending on road category or design speed which based on foreign practice depends on the least applicable length of vertical curve tangent;

- It is essential in road design - seen as the final look of the road for the driver - that road design standards should be respected in all design phases by all members of the design team, mainly by the geometric designer who has the very difficult task of modelling the three dimensional sculpture consisting of the road and its environment. Therefore, it is necessary to change their own standards to integrate new methods of road design and specifically the influence of spatial perception and optical guidance on users. 


\section{References}

[1] World Road Association (PIARC). 2012. Human Factors in Road Design. Review of Design Standards in Nine Countries. Report 2012R36 of Technical Committee C.1 Safer road infrastructure. ISBN 978-2-84060-306-1.

[2] Forschungsgesellschaft für Straßen- und Verkehrswesen e.V. 2012. Richtlinien für die Anlage von Landstraßen (RAL). Köln, 137 p.

[3] Forschungsgesellschaft für Straßen- und Verkehrswesen e.V. 2008. Richtlinien für die Anlage von Autobahnen (RAA). Köln, 120 p.

[4] CROW te Ede. 2002. Handboek Wegontwerp Gebiedsontsluitingswegen. Dutch . 264 p. ISBN: 9066283572.

[5] CROW te Ede. 2002. Handboek Wegontwerp Basiscriteria. Dutch . 140 p. ISBN: 9066283548

[6] CROW te Ede. 2002. Handboek Wegontwerp Erftoegangswegen. 120 p. ISBN: 9066283556.

[7] American Association of State Highway and Transportation Officials (AASHTO). 2011. A Policy Geometric Design Highways and Streets. Washington, $870 \mathrm{p}$

[8] The Highways Agency. 2013. Design Manual For Roads And Bridges. UK, Volume 15. Available from Internet: gopher: www.dft.gov.uk. [9] Keliu techninis reglamentas KTR 1.01:2008 „Automobilių keliai“. 